\section{By the Way...}

Carine Tarazi', Pierre Gressens ${ }^{2}$ and Olaf Dammann ${ }^{3}$

$\mathrm{F}$ ive years ago, Chief Editors Sherin Devaskar and Petra Hüppi were looking back at their $7 \mathrm{y}$ of work on the Journal and the foundational changes we take for granted today. Most importantly, they had moved Pediatric Research from a paperbased submission and review process to a web-based one. They had also divided the Table of Contents into Basic, Translational, and Clinical articles, and had introduced both the monthly Focus Page and the annual Review Issue. ${ }^{1}$ After this tremendous work, they turned the Journal over to our care.

A few other big changes were occurring at that point in time. The shift to Nature Publishing Group extended our capabilities and expanded our audience. We went from designing our own covers the first year to having our pick of images in NPG's stock. We now have a bimonthly podcast, Pediapod, for which authors are interviewed regarding their work. Stephanie Dean came on board as an efficient and very talented Managing Editor, always ready to hear ideas, field questions, run communications, make contributions, and ensure that the Journal was running smoothly. During that time, we also transitioned to a new manuscript submission system, eJournal Press, which meant that we all-editors, reviewers, and publisher-had our work cut out for us.

In the editorial that began our tenure as Chief Editors, we stated three goals for Pediatric Research. ${ }^{2}$ The first was the further internationalization of the editorial board. Since then, Editors who work from China, India, Turkey, India, and New Zealand have been added. We hope that the Journal will continue on the path to a truly worldwide perspective on child health. Our second goal was expansion of the scope and impact of the Journal. We introduced the Population category of papers and added Systematic Reviews in the type of reviews published by Pediatric Research. We launched Integrated Mechanism Reviews, ${ }^{3}$ which we hope will provide myriad avenues for research. We also published a considerable number of papers in the fields of public health and epidemiology, previously underrepresented in the Journal. Last, we encouraged young investigators in their research. We introduced the Junior Author Best Paper travel award that has funded young authors' attendance at the yearly meeting of the Pediatric Academic Societies or the European Society of Paediatric Research.

We rarely used our role as Chief Editors to influence the words people chose. One exception, however, is the editorial ${ }^{4}$ we published strongly discouraging use of the phrase "hypoxic-ischemic encephalopathy," and in favor of the term "neonatal encephalopathy." Our rationale was and is that the etiology of neonatal encephalopathy is heterogeneous and perhaps only infrequently includes lack of oxygen and insufficient blood flow. Some disagreed ${ }^{5}$ while others supported our views. ${ }^{6,7}$ We continue to believe that words matter.

We extend our heartfelt thanks to our Section Editors, Editors, and reviewers. Your expertise will continue to serve the medical community in its pursuit of knowledge. We are sincerely grateful to those with Nature Publishing Group: Steven Ottogalli, our publishing manager, who expertly advised us on many journal-related matters; Erin Dewalt, a graphic designer at Nature, who always gives us a wealth of cover design options; and Charlotte Stoddart and Kerri Smith, in London, who have conducted interviews for Pediapod with great perspicacity. Additionally, the IPRF Board of Trustees has avidly supported the Journal, in terms of funding new endeavors and ensuring the long-term health of the Journal. Their expert counsel has been greatly appreciated.

Pediatric Research has undergone a steady evolution and there is every reason to be confident about its future. The Journal is switching over to another editorial management system in the upcoming months, and we wish for a smooth transition on that front. We look forward to the positive changes our successors, Dr Cynthia Bearer and Dr Eleanor Molloy, will make as the Journal grows further.

\section{REFERENCES}

1. Devaskar SU, Hüppi PS. The state of the journal-Pediatric Research: the last seven years-where we were and how far we have come. Pediatr Res 2010;68:461.

2. Dammann O, Gressens P. Pediatric research: tradition and transition. Pediatr Res 2011;69:1

3. Dammann O, Gressens P. Integrated mechanism reviews. Pediatr Res 2012;71:530-1.

4. Dammann O, Gressens P. Neonatal encephalopathy or hypoxic-ischemic encephalopathy? Appropriate terminology matters. Pediatr Res 2011;70:1-2.

5. Volpe JJ. Neonatal encephalopathy: an inadequate term for hypoxicischemic encephalopathy. Ann Neurol 2012;72:156-66.

6. Wu Y. Brain injury in newborn babies: we can't afford to get it wrong. Ann Neurol 2012;72:151-2.

7. Leviton A. Why the term neonatal encephalopathy should be preferred over neonatal hypoxic-ischemic encephalopathy. Am J Obstet Gynecol 2013;208:176-80. 